higher on the French side than those on the English side; and in the St. George's Channel, where the tidal ranges are higher on the Welsh coast than on the Irish coast.

The phenomenon becomes still more interesting when, in the rotating channel, there are two sets of waves proceeding in opposite directions. The effect of uniting the two waves which will have the higher part of their crests on opposite shores is to produce a set of amphidromic points. These are points at which there is no tidal rise and fall of the water level. The points are (under uniform conditions) placed at equal distances down the centre line of the channel. Leading from each amphidromic point is a tidal crest which sweeps round the amphidromic point rather like the hand of a clock (though not necessarily straight) in the period of the tidal oscillation. The channel is thus divided up into separate, independent and similar systems. The tidal range increases as we pass from the amphidromic point outwards along the tidal crest.

The main amphidromic point in the North Sea is over the Dogger Bank, and the tidal crest sweeps down the English coast from north to south and then up the Belgian coast from south to north. A modification is made by the existence of a smaller system of the same kind in the Flemish Bight.

Similar phenomena are found in the English Channel though the amphidromic point is in Wilt. shire ; and in St. George's Channel where the amphidromic point is in Wexford.

Referring to the effect of wind in altering the mean water level, both theory and observation show that the wind blowing steadily along the surface of the open sea causes a surface drift of the water in a direction inclined at $45^{\circ}$ to the right of the wind in the northern hemisphere and a general drift at $90^{\circ}$ to the right of the wind direction. In the southern hemisphere the corresponding effects are $45^{\circ}$ and $90^{\circ}$ to the left of the wind direction. The combination of a strong north-west wind with the perigean tides affords an explanation of the recent flooding of the East Anglian coasts.

\title{
Child Nutrition
}

\begin{abstract}
A NORTHUMBERLAND and Durham Conference on Child Nutrition, organized by the Children's Minimum Council, was held in Newcastleon-Tyne on May 14. Prof. V. H. Mottram, professor of physiology in King's College of Household and Social Science, University of London, who was one of the principal speakers, posed five questions to which the scientific nutrition expert should be able to give unequivocal answers : namely,
\end{abstract}

(1) What is meant by an adequate diet ?

(2) What is the minimal cost of such a diet ?

(3) Is the cheapest adequate diet either dietetically or psychologically possible?

(4) Even if this diet of minimal cost were practicable, could everyone afford it ?

(5) Is there indisputable evidence that many children are not able to get adequate nourishment ?

In his answer to the first question, Prof. Mottram covered dietetic ground familiar to most readers of NATURE. He stressed in particular the value of milk and fruit as sources of the 'protective' factors of diet. The cheapest diet containing all the necessary constituents in adequate amounts and proper pro. portions consists of cheese, coarse brown bread and raw cabbage. This would entail no cooking and very little preparation, but would be neither easy to eat nor very digestible. One must consider not only the theoretical value of a diet as purchased but also its 'availability', satiety value and psychological effect. Hunger may be the best sauce, but monotony drives appetite away.

Even so, this primitive and unappetizing pabulum (one dare not dignify it with the title of diet) would cost at least 4/9 per 'man' per week, a sum beyond the purse of more than a tenth of the population of Britain. That is, from purely theoretical con. siderations many people are markedly underfed, while many more-about two fifths to one half-must have dietaries lacking in some of the so-called protective foods. There is no difficulty about the supply of sufficient energy-giving foodstuffs. Calories are cheap-a thousand for a penny-but vitamincontaining foods are relatively expensive.

Is there, however, actual evidence of undernutrition? Nutrition has been given a wider connotation in medical literature than in common speech, which from the point of view of the man-in-the-street is a pity as undefined terms or terms used to cover various meanings lead, and in this instance have led, to bitter wrangling. Using the common meaning of the word, evidence can be produced that malnutrition is too common to be neglected if we wish for a fit nation now or in the immediate future. For example, some 25 per cent of the children in or around London suffer from a lack of a fat-soluble vitamin derived from milk, butter, carrots, etc. This is shown by defective vision in twilight. Even university students, because of the absence of citrous fruit and/or fresh meat in their diet, have been known to show the signs of latent scurvy or even actual scorbutic gums. Lady Mellanby has demon. strated that bad teeth in children were to a great extent due to a low intake of the vitamin D complex found in summer milk and butter.

To some extent, these defects are being overcome by the provision of school meals and milk in schools, and by the provision of cheap or free milk to necessitous nursing mothers and their infants. There is, however, no service to cover the gap between the infant welfare period and the school age. During these three years, irreparable damage may be done. "The schools", said Prof. Mottram, "start with damaged goods"'. The process of repair is more costly than proper building and, as Lady Mellanby has proved for teeth, 'repair' generally means covering up shoddy material and jerry building with layers of good material. No matter how soundly this later building may be done, the whole structure is rotten at the core.

Miss Rathbone, M.P. for the Northern Universities, urged that immediate action should be taken to remedy this state of affairs, and dealt with the various reasons why schemes at present in operation are only partially effective.
D. B. 